Article

\title{
The hns Gene of Escherichia coli Is Transcriptionally Down-Regulated by (p)ppGpp
}

\author{
Anna Brandi, Mara Giangrossi, Attilio Fabbretti and Maurizio Falconi *(D) \\ School of Biosciences and Veterinary Medicine, University of Camerino, 62032 Camerino, Italy; \\ anna.brandi@unicam.it (A.B.); mara.giangrossi@unicam.it (M.G.); attilio.fabbretti@unicam.it (A.F.) \\ * Correspondence: maurizio.falconi@unicam.it; Tel.: +39-0737-403274
}

Received: 25 August 2020; Accepted: 8 October 2020; Published: 10 October 2020

check for updates

\begin{abstract}
Second messenger nucleotides, such as guanosine penta- or tetra-phosphate, commonly referred to as (p)ppGpp, are powerful signaling molecules, used by all bacteria to fine-tune cellular metabolism in response to nutrient availability. Indeed, under nutritional starvation, accumulation of (p)ppGpp reduces cell growth, inhibits stable RNAs synthesis, and selectively up- or down- regulates the expression of a large number of genes. Here, we show that the E. coli hns promoter responds to intracellular level of (p)ppGpp. hns encodes the DNA binding protein H-NS, one of the major components of bacterial nucleoid. Currently, H-NS is viewed as a global regulator of transcription in an environment-dependent mode. Combining results from relA (ppGpp synthetase) and spoT (ppGpp synthetase/hydrolase) null mutants with those from an inducible plasmid encoded RelA system, we have found that $h n s$ expression is inversely correlated with the intracellular concentration of (p)ppGpp, particularly in exponential phase of growth. Furthermore, we have reproduced in an in vitro system the observed in vivo (p)ppGpp-mediated transcriptional repression of hns promoter. Electrophoretic mobility shift assays clearly demonstrated that this unusual nucleotide negatively affects the stability of RNA polymerase- $h n s$ promoter complex. Hence, these findings demonstrate that the $h n s$ promoter is subjected to an RNA polymerase-mediated down-regulation by increased intracellular levels of (p)ppGpp.
\end{abstract}

Keywords: hns; guanosine penta-tetra-phosphate; stringent response; transcriptional regulation

\section{Introduction}

The signaling molecules guanosine-tetraphosphate (ppGpp) and guanosine-pentaphosphate (pppGpp), collectively named (p)ppGpp, are the main mediators of "stringent response," a common phenomenon occurring when bacteria face environmental stresses [1-3]. Two enzymes are responsible for the production of (p)ppGpp, the major RelA synthase, and the SpoT degradase that displays both (p)ppGpp degradation and synthetic activity [4]. In particular, when bound to ribosome, the RelA enzyme senses through its autoinhibitory domain and is being activated by the entrance of uncharged tRNAs into the ribosomal A-site, a circumstance occurring during amino acid starvation [5]. Thus, nutrients limitation causes an intracellular accumulation of (p)ppGpp that dramatically alters bacterial physiology and metabolism [6]. Under this condition, indeed, growth rate is slowed, stable RNA (rRNA and tRNA) production is inhibited, and the high levels of modified nucleotide differentially up- or down-regulate the expression of a large number of genes. The stringent response has been investigated for half a century, and solid evidence for (p)ppGpp acting directly on RNA polymerase (RNAP) has been already reported $[7,8]$. However, only two recent studies have provided deeper insights into the mechanism of action exerted by (p)ppGpp in modulation of transcription initiation from specific promoters; (p)ppGpp was found to target the E. coli RNAP and two binding sites for this alarmone have been localized on the core enzyme $[9,10]$. In fact, the first site is at the interface of $\beta^{\prime}$ 
and $\omega$ subunits of RNAP, while the second one originates from the contact point of the transcription factor DksA with RNAP. Recently, by means of high-throughput sequencing technologies (RNA-seq), a complete collection of E. coli promoters, controlled in vivo by (p)ppGpp, has been provided [11]. This study shows that 757 genes are up- or down-regulated (at least twofold) within five minutes of continuous production of (p)ppGpp through the conditional expression of a mutated RelA lacking its autoinhibitory domain. Even if Sanchez-Vazquez et al. [11] widened the list of (p)ppGpp-responding promoters ( $75 \%$ were not previously identified), under the experimental conditions used, the $h n s$ gene encoding the Histone-like Nucleoid Structuring (H-NS) protein was not identified. Similarly, also Aberg et al. [12] did not find any (p)ppGpp-dependent changes of $h n s$ expression by a microarray analysis.

The H-NS protein has been extensively investigated in our laboratory, and its biochemical characterization and the regulation of this gene date back to the late 1980s [13-15]. Currently, H-NS, in addition to its well-established role in the organization of bacterial chromatin, is recognized as a "universal repressor" involved directly or indirectly in the regulation of numerous genes ( 200), most of them linked to stress responses and bacterial pathogenesis [16-19]. The basis for H-NS function as a gene silencer resides in its preferential binding to AT-rich curved DNA sequences [20,21], often found upstream of E. coli promoters and in its ability to induce bending of noncurved DNA [22], thus altering DNA conformation/topology and/or competing with RNAP and other regulators [23-26]. Genome-wide functional analyses have mapped 1000 sites bound by H-NS, accounting for the regulation of $5 \%$ of the entire E. coli genome [27], including DNA sequences of exogenous origin acquired by horizontal gene transfer [28,29].

In a previous study [30], we have found that the activation of hns, upon cell resumption from stationary phase, is partially abolished by high levels of (p)ppGpp. Here, we have provided a deeper investigation on the role of (p)ppGpp in the regulation of $h n s$, showing that in vivo level of $h n s \mathrm{mRNA}$ inversely correlates with the intracellular concentration of the modified nucleotide. Accordingly, we show that (p)ppGpp is able to inhibit $h n s$ promoter activity through in vitro transcription assay, suggesting a direct action of this molecule on the RNA polymerase. This finding is further supported by electrophoretic mobility shift assays (EMSA) that reveals a (p)ppGpp-mediated destabilization of RNAP-hns promoter complex.

\section{Materials and Methods}

\subsection{Bacteria Strains}

E. coli strains used in this study were: MRE600 (F-,rna) [31]; CF2676 (argA::Tn10, relA+) an N99 derivative (F-, galK2, rpsL, lambda-) [32,33]; CF1753 (argA::Tn10, relA1) an MG1655 derivative (K12 strain, F-, lambda-, ilvG-, rfb-50, rph-1) [33]; CF3042 (zib563::Tn10, spot203, relA1) an N99 derivative [33,34]; KT793 carrying IPTG inducible RelA protein from pKT31 or a truncated form from pKT40 [35]. E. coli cells were grown at $37{ }^{\circ} \mathrm{C}$ in Luria-Bertani (LB) broth supplemented with $0.5 \%$ glucose [36] or in "Phosphates-free" medium (100 mM Tris- $\mathrm{HCl}$, pH 7.7, 0.5\% peptone, $10 \mathrm{mM} \mathrm{NH}_{4} \mathrm{Cl}, 0.7 \mathrm{mM} \mathrm{NaNO}_{3}$, $\left.1 \mathrm{mM} \mathrm{Na}_{2} \mathrm{SO}_{4}, 0.5 \mathrm{mM} \mathrm{MgSO}_{4} \cdot 7 \mathrm{H}_{2} \mathrm{O}, 0.05 \mathrm{mM} \mathrm{MnCl}_{2} \cdot 4 \mathrm{H}_{2} \mathrm{O}\right)$.

\subsection{DNA Manipulation and General Procedures}

Total RNA purified by hot phenol extraction [37] was subjected to northern blot and the $h n s$ mRNA was detected by using a specific $5^{\prime}$-end-labeled oligonucleotide (5'-GCGCACGAAGAGTACGG-3') or [ $\left.{ }^{32} \mathrm{P}\right]-$ labeled $h n s$ probes obtained from pPLc11 [38] and labeled by random primer reaction [36]. The radioactivity associated to $h n s$ mRNA, normalized for $16 \mathrm{~S}$ rRNA, was quantified by Molecular Imager FX (Bio-Rad, Hercules, CA, USA). Thin layer chromatography was performed as previously described [39] and quantified by Molecular Imager FX (Bio-Rad).

\subsection{In Vitro Transcription}

In vitro transcription assays were programmed with pKK400::cat, a pKK232-8 derivative, carrying the $h n s$ promoter and its upstream regulatory region up to position -313 [15]. Multiple round 
transcription reactions were carried out at $37{ }^{\circ} \mathrm{C}$ in a total volume of $45 \mu \mathrm{L}$ transcription buffer, essentially as previously described, [30] and mRNA synthesized in vitro was determined by northern analysis using a [32P]-labeled cat probe derived from pCM7 (Pharmacia, New Jersey, NJ, USA). Radioactivity was quantified by Molecular Imager FX (Bio-Rad).

\subsection{Electrophoretic Mobility Shift Assays}

The 221 bp DNA fragment carrying the hns promoter (from position -159 to position +62 ) was amplified by PCR using as template pKK600 [15] and the primers Gen405 (5'-TTCAGAATTTTAAGT GCTTCGCTCA-3') and Gen406 (5'-GTGCTGCGAAATCATCGGTGTAAA-3'). The oligonucleotide Gen406 used in PCR was previously radiolabeled with T4 kinase and [ $\left.\gamma_{-}{ }^{32} \mathrm{P}\right]-\mathrm{ATP}[36]$. Reaction mix contained the labeled DNA $(\sim 0.3 \mathrm{pmol})$ and purified RNA polymerase $(7 \mathrm{pmol})$ in $200 \mu \mathrm{L}$ of Binding Buffer (40 mM Hepes KOH pH 8, 50 mM KCl, 10 mM MgAcetate, 0.5 mM 1,4-Dithiothreitol DTT and $0.005 \% \mathrm{NP} 40$ ). The reaction mix was divided into two tubes: the first one containing ribo-Adenosine $5^{\prime}$-triphosphate (ATP) (final conc. $50 \mu \mathrm{M}$ ) and the second one containing the same amount of ribo-ATP and ppGpp (final conc. $500 \mu \mathrm{M}$ ). The two tubes were incubated at $30^{\circ} \mathrm{C}$ and aliquots $(15 \mu \mathrm{L}$ ) were withdrawn in a time course experiment. Binding of RNA polymerase to the DNA probe was stopped by adding $5 U$ of heparin and placing the samples in ice before loading on a native acrylamide gel (6\%). Radioactivity associated to free and bound DNA was quantified by Molecular Imager FX (Bio-Rad).

The E. coli RNA polymerase was purified according to Gross et al. [40]. The amounts of all polymerase subunits (polypepdide chains $\beta, \beta^{\prime}, \alpha$, and $\omega$ ) and $\sigma$ factor in the preparation were determined by sodium dodecyl sulfate (SDS)-polyacrylamide gel electrophoresis and the RNAsynthesizing capacity was verified in an in vitro transcription assay (not shown).

\section{Results}

\subsection{Low Levels of ( $p$ )pp Gpp Stimulate hns Expression}

The role of (p)ppGpp on hns expression was initially investigated by means of antibiotics as chloramphenicol (CAM) and kanamycin (Kan), which were known to affect the intracellular level of this unusual nucleotide. In fact, these two drugs, by blocking protein synthesis, have been shown to cause a dramatic reduction in (p)ppGpp [41]. Thus, to verify whether (p)ppGpp could regulate $h n s$ expression, the level of hns mRNA was monitored in a time course experiment after treating the cell with high doses of CAM and Kan. As seen in Figure 1, both drugs behave similarly by triggering a prompt increase ( $\sim$ threefold) of hns transcript compared to the untreated cells as control. Steady-state level of hns mRNA was further investigated using a strain defective for RelA synthetase, the enzyme catalyzing (p)ppGpp production along with double mutant relA/spoT that, in addition to relA, carried an inactivated bifunctional (p)ppGpp synthetase/hydrolase SpoT. Xiao et al. [33] found that glucose exhaustion during cell growth provoked (p)ppGpp accumulation. Thus, the level of this effector progressively diminished passing from wild type (wt) to relA and from relA to relA/spoT backgrounds. Accordingly, northern analysis demonstrates that basal level of hns transcript (Figure 2A, time 0), shows $\sim$ three- and sevenfold increase in relA and relA/spoT mutants, respectively, compared to wt strain. In addition, chloramphenicol treatment induces a sudden burst of hns expression in all the strains considered, even if at different extents with respect to the intrinsically different constitutive levels of $h n s$ mRNA (Figure 2A,C). Indeed, the lower the basal steady-state level, the greater is the induction of $h n s$ transcription caused by the CAM-dependent reduction in (p)ppGpp. Thus, this stimulation decreases from wt (fivefold) to relA/spoT (1.4-fold) through relA (twofold) cells; given that the intracellular level of (p)ppGpp is already very low in relA/spoT strain, CAM effects are almost completely lost in this double mutant (Figure 2C). To reinforce this finding, the level of hns transcript was measured during cell growth in wt and relA/spoT strains. Northern analysis reveals that hns expression is $\sim$ twofold higher in double mutant compared to wt cells in the exponential phase of growth $\left(\mathrm{A}_{600}<1\right)$ and this difference gradually disappears as the cells approach the stationary phase $\left(\mathrm{A}_{600}>1.5\right)($ Figure $2 \mathrm{~B}, \mathrm{D})$. 
Taken together, these results strongly suggest that $h n s$ expression is inversely correlated with the intracellular concentration of (p)ppGpp.
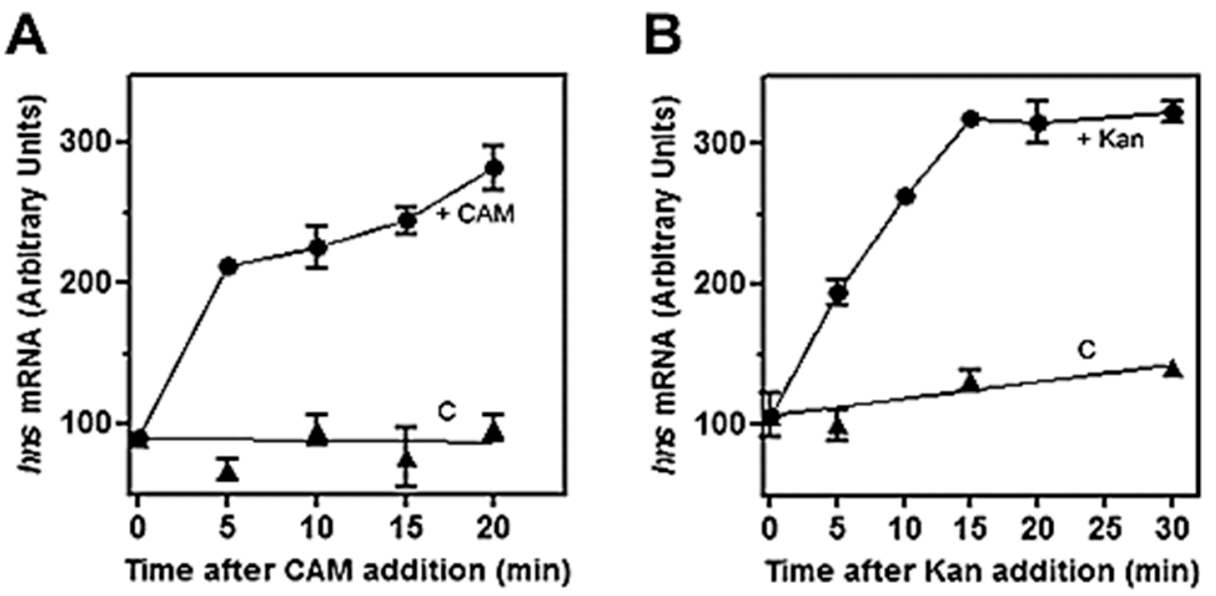

Figure 1. Effects of chloramphenicol and kanamycin on $h n s$ transcription in vivo. The E. coli strain MRE600 was grown at $37^{\circ} \mathrm{C}$ in LB broth up to $\mathrm{Abs}_{600}=0.5-0.6$ (exponential phase of growth) and at the indicated times after the addition of $200 \mu \mathrm{g} / \mathrm{mL}$ of chloramphenicol (A) or $300 \mu \mathrm{g} / \mathrm{mL}$ of kanamycin (B), cell aliquots were harvested for RNA extraction. About $10 \mu \mathrm{g}$ of total RNA were subjected to northern blot analysis and membranes hybridized with a [23 P]-labeled $h n s$ probe. Treated cells $(\bullet)$ and control culture (C) in the absence of drugs $(\mathbf{\Lambda})$ are shown. Data represent the average of at least two independent experiments and standard deviation is reported.

A

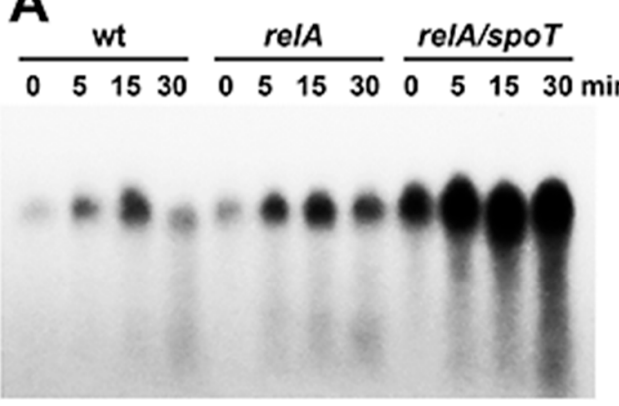

B

C

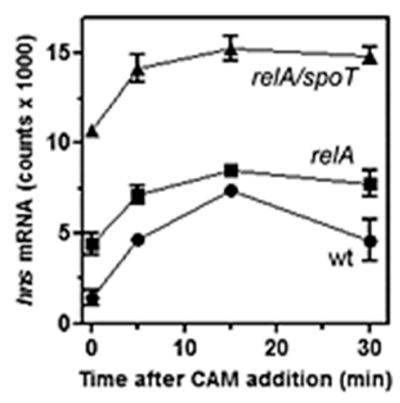

D

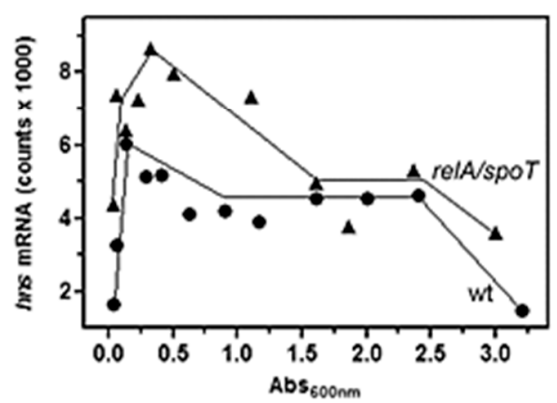

$\begin{array}{lllllll}.9 & 1.2 & 1.6 & 2 & 2.4 & 3.2 & \mathrm{ON}\end{array}$

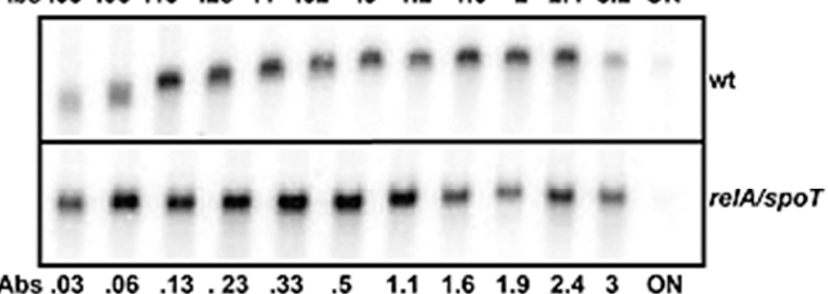

E

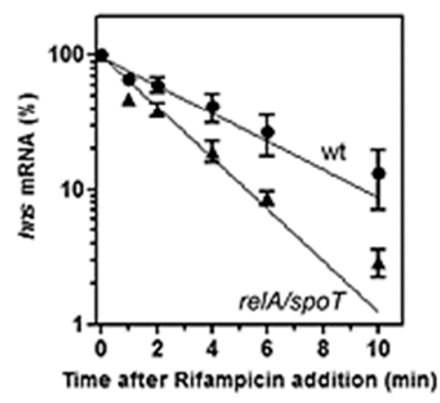

Figure 2. Chloramphenicol and mutations of relA and spoT genes induce hns transcription in vivo.

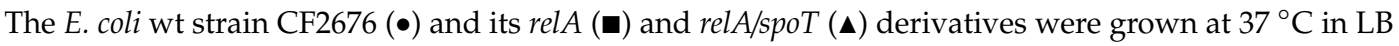
broth up to the exponential phase $\left(\operatorname{Abs}_{600}=0.5-0.6\right)$. Then the steady-state level of $h n s$ mRNA was monitored by northern analysis at the indicated times after addition of chloramphenicol $(200 \mu \mathrm{g} / \mathrm{mL})$ (A) and as a function of the cell density $\left(\mathrm{Abs}_{600}\right)(\mathbf{B})$. Lanes indicated with 0 in panels $\mathrm{A}, \mathrm{C}$, and $\mathrm{E}$ represent the hns mRNA levels in cells before drug addition, while ON in panel B is for Overnight Culture. Panels (C) and (D) show the quantifications of blots A and B, respectively. Determination of 
the chemical stability of $h n s$ mRNA in wt $(\bullet)$ and $r e l A / s p o T(\mathbf{\Lambda})$ strains (E). Cultures at $\mathrm{A}_{600 \mathrm{~nm}}=0.5$ were treated with rifampicin $(250 \mu \mathrm{g} / \mathrm{mL})$ at time zero whose $h n s$ level is taken as $100 \%$. After drug addition, RNA was extracted from cells harvested at the indicated times. The level of $h n s$ transcript was determined by northern blot hybridized with a $\left[{ }^{32} \mathrm{P}\right]$-labeled $h n s$ probe. Data represent the average of at least two independent experiments and standard deviation is reported.

Furthermore, to explore whether the higher amounts of hns transcript in cells carrying mutations in relA and spot $T$ genes might simply reflect a stabilization of mRNA rather than an activation of $h n s$ promoter, the decay rate of hns mRNA was analyzed, comparing wt and relA/spotT double mutant after blocking the transcription by rifampicin (Figure $2 \mathrm{E})$. The half-life $\left(\mathrm{t}_{1 / 2}\right)$ of $h n s$ message, expressed as the time required for degrading $50 \%$ of the existing mRNA molecules, slightly changes in the two different genetic backgrounds, being $t_{1 / 2}=2.0 \mathrm{~min}$ and $t_{1 / 2}=1.2 \mathrm{~min}$ for wt and relA/spoT strains, respectively. Notably, the chemical stability of $h n s$ mRNA is higher in wt than in double mutant, ruling out that RNA $t_{1 / 2}$ can account for the elevated levels of $h n s$ transcript observed in relA/spoT cells. Thus, these findings indicate that the hns promoter is responsive to (p)ppGpp, and the low level of this unusual nucleotide, as a consequence of the inactivation of relA and spoT genes, induces de novo transcription of hns.

\subsection{High Levels of ( $p$ )ppGpp Directly Repress hns Promoter}

According to our previous observations [30], we tested the effect of high amounts of (p)ppGpp, linked to amino acid starvation, on the promoter activity of hns. To this aim, the intracellular (p)ppGpp levels were artificially increased by overexpressing the RelA alpha fragment in plasmid pKT31, carrying the (p)ppGpp catalytic domain independent of ribosome binding. The isogenic plasmid pKT40, because of the insertion of a stop codon in relA gene, encoded a truncated protein and was used as control. The production of functional RelA and its inactivated variant from pKT plasmids was achieved by adding IPTG to the cell cultures [35]. The nutritional upshift, as consequence of moving stationary-phase cells to a fresh medium not supplemented with IPTG, causes an abrupt burst ( threefold) of hns transcription (Figure 3A). Conversely, the accumulation of (p)ppGpp from pKT31 in induced cells, as determined by thin layer chromatography (Figure 3B,D), completely abolishes the transcriptional activity of $h n s$ promoter (Figure 3A). As control, the expression of a nonfunctional RelA enzyme from pKT40 does not affect the hns mRNA level regardless of IPTG induction (Figure 3C).

These results suggest that (p)ppGpp exerts a targeted repressive action on hns promoter, encouraging us to better investigate the effect of (p)ppGpp on hns transcription through an in vitro purified system as a function of increasing concentrations of this alarmone. As shown in Figure 4A,B, the addition of $0.5 \mathrm{mM}$ of (p)ppGpp results in a residual hns transcription of $\sim 10 \%$ and hns::cat mRNA becomes undetectable when this regulatory nucleotide is present at $1 \mathrm{mM}$, value that corresponds to the concentration estimated in vivo after amino acids starvation [42]. Importantly, suboptimal concentrations of (p)ppGpp (below $0.5 \mathrm{mM}$ ) that are not able to completely shut down the hns promoter activity, indeed causes the appearance of truncated cat transcripts (Figure 4A) as products of premature arrests of mRNA synthesis. This is possibly due to the pausing of RNA polymerase at transcriptionally unfavorable regions. 
A
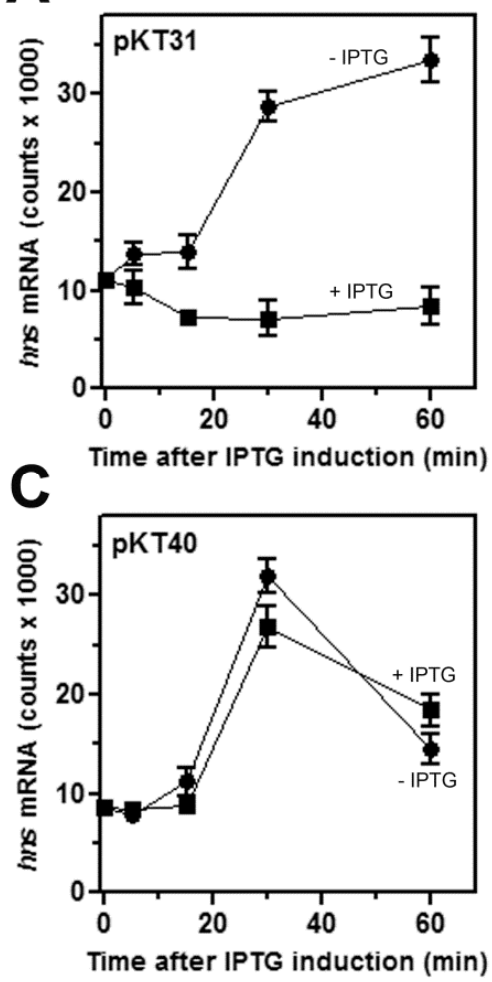

B

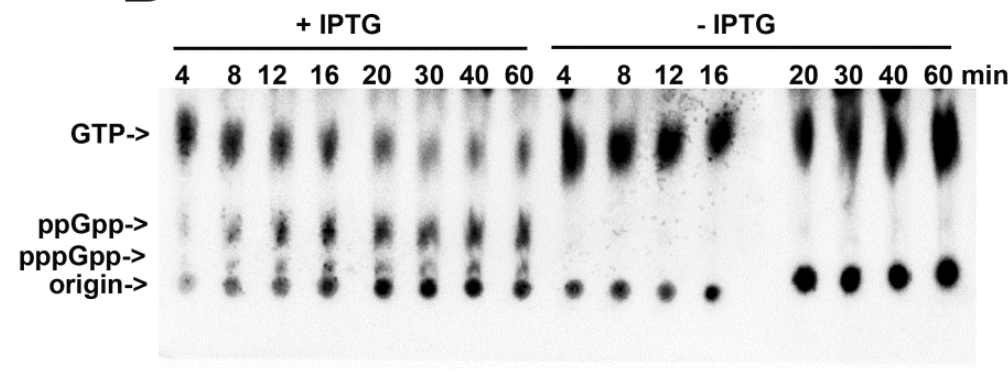

D

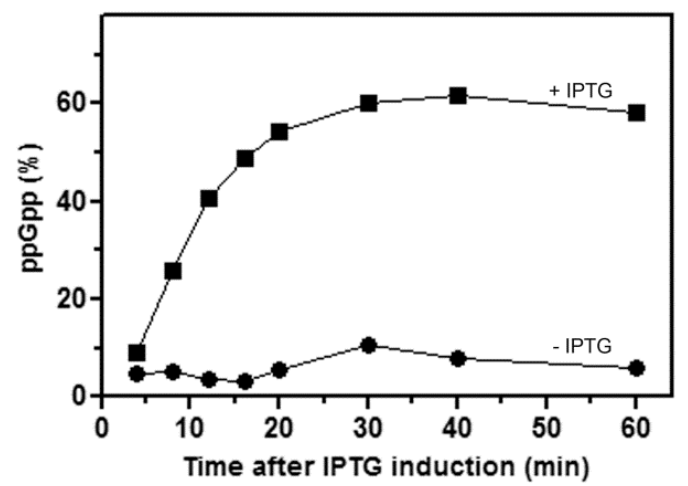

Figure 3. High levels of (p)ppGpp inhibit hns transcription in vivo. The level of hns transcript was monitored during growth in Phosphates-free medium at $37^{\circ} \mathrm{C}$ in E. coli cells (KT793) expressing (A) or not (C) an active RelA synthetase. RNA to be subjected to northern blotting analysis was extracted from cells in stationary phase (time, $0 ; \mathrm{Abs}_{600 \mathrm{~nm}} \cong 3.0$ ) and at the indicated times after a 10-fold dilution of cultures with fresh medium alone $(\bullet)$ or supplemented with $400 \mu \mathrm{M} \mathrm{IPTG}(\boldsymbol{\square})$ to activate the lacUV5::relA gene. [ $\left.{ }^{32} \mathrm{P}\right]$-labeled pppGpp, ppGpp and GTP, in IPTG-induced and not-induced pKT31 transformants, were resolved by thin layer chromatography (B) and radioactivity quantified by Molecular Imager. ppGpp, was expressed as percentage (\%) of the total guanine nucleotides (D). The (p)ppGpp accumulation was not observed in IPTG-induced cells harboring plasmid pKT40 (not shown).

Ross et al. $[9,10]$ demonstrated that (p)ppGpp was able to regulate transcription initiation from sensitive promoters by directly interacting with RNA polymerase. Thus, according to those findings and our in vitro transcription results (Figure 4), we explored the effects of (p)ppGpp on the interaction of RNAP with the promoter region of hns. The yield of DNA-RNAP complexes was investigated by electrophoretic mobility shift assay (EMSA) performed as a function of increasing periods of time without and with a fixed concentration of (p)ppGpp (Figure 5A). To convert unstable complexes into stable initiation complexes, the start ribonucleotide ATP was added. The RNAP-hns promoter binding kinetic was followed in a time course experiment and stopped using heparin, which, by irreversibly interacting with the free enzyme, prevented the aggregation of additional DNA-RNAP complexes [43]. As shown in Figure 5B, (p)ppGpp considerably slows down the formation of RNAP-hns promoter complex that is reflected in at least threefold reduction in the association constant $\left(\mathrm{K}_{\mathrm{a}}\right)$. Summarizing, EMSA results suggest that (p)ppGpp negatively affects the extent of complexes trapped in transcription that are therefore considered to be productive, hence accounting for transcriptional inhibition of $h n s$ promoter by (p)ppGpp as observed both in vivo and in vitro as well (Figures 3 and 4). 
A

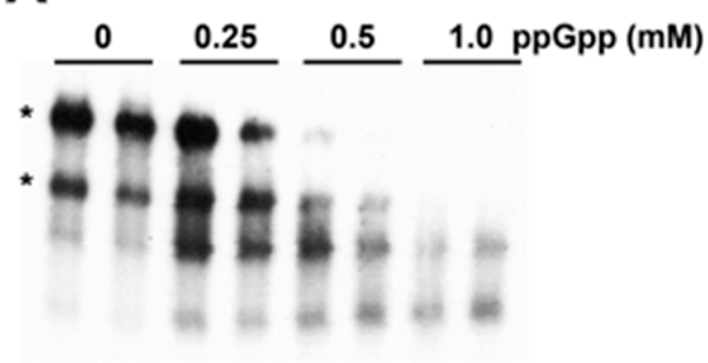

B

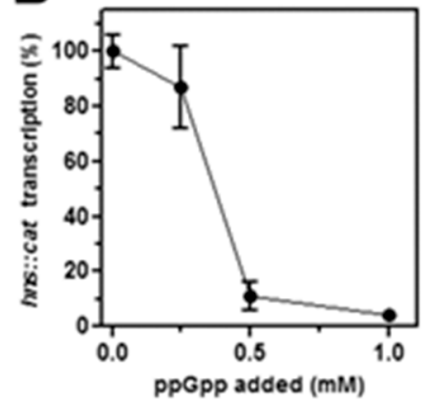

Figure 4. (p)ppGpp represses the in vitro transcription of hns. The activity of hns promoter was investigated by an in vitro assay as a function of increasing concentrations of (p)ppGpp. The supercoiled plasmid pKK400::cat ( 100 ng) used as DNA template was incubated for $10 \mathrm{~min}$ at $37^{\circ} \mathrm{C}$ with the E. coli RNA polymerase and the indicated amounts of (p)ppGpp. Then, transcription was stopped, and RNA analyzed by northern blot hybridized with a [ $\left.{ }^{32} \mathrm{P}\right]$-labeled cat probe obtained from pCM7 (Pharmacia) (A). Asterisks indicate the two cat mRNAs that start from the hns promoter and end at the rrnB ribosomal RNA T1 or T2 terminators located downstream cat gene on pKK400. Transcription is expressed as percentage (\%) taking the mRNA level in absence of (p)ppGpp as $100 \%$ (B). Reactions and processing of samples are described in detail in Materials and Methods. A representative gel is shown, and data correspond to the average of two independent experiments with duplicated points and standard deviation.
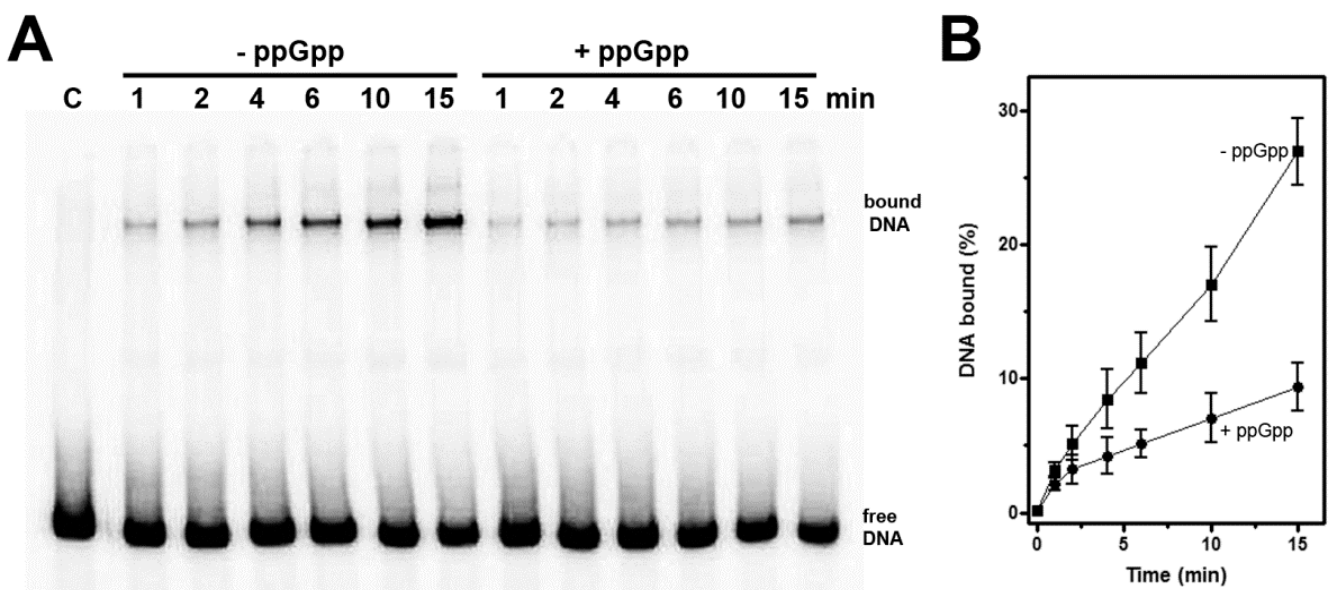

Figure 5. (p)ppGpp destabilizes the RNAP-hns promoter complex. EMSA was carried out as described in Materials and Methods by incubating for the indicated times, a [ $\left.{ }^{32} \mathrm{P}\right]$-labeled DNA fragment (221 bp), corresponding to $h n s$ promoter with RNA polymerase in the absence or presence of ppGpp (500 $\mu \mathrm{M})$ (A). The electrophoretic migrations of free DNA and hns DNA-RNAP complex are indicated and C is the control sample in absence of protein. Radioactivity associated to free and bound DNA was quantified and complexed DNA has been expressed as percentage (B). A representative gel is shown, and the average of four independent experiments and standard deviation are reported.

\section{Discussion}

Bacterial cells, lacking homeostatic mechanisms, withstand changes in environmental conditions, deeply reshaping transcriptional activity. Hence, prompt adaptation to stresses, in particular to amino acid starvation, is coupled with an intracellular accumulation of the second messenger (p)ppGpp, also known as "magic spot". This signaling molecule modulates the stringent response by affecting several fundamental cellular processes, including transcription.

In this study, we demonstrate that the expression of hns gene, coding for the DNA-binding protein H-NS, is under control of (p)ppGpp. Specifically, treatments with antibiotics capable of arresting the 
protein synthesis and null mutations in relA and spoT genes responsible for (p)ppGpp production reduce the alarmone level and as consequence elicit an activation of $h n s$ promoter in vivo (Figures 1 and 2). Conversely, artificially increasing (p)ppGpp by a recombinant RelA-based system, causes a severe inhibition of the activity of $h n s$ promoter (Figure 3). According to these findings and since (p)ppGpp dramatically reprograms the entire transcription profile of bacterial cell, the fact that a regulatory gene as $h n s$ is a preferential target of this alarmone is not surprising, and may reflect a valid strategy to enhance the regulative ability of (p)ppGpp itself. In fact, H-NS, besides its role in DNA-packaging and nucleoid organization, shows high pleiotropic effects, and is currently considered as a global repressor of transcription in bacteria. The majority of genes belonging to H-NS regulon are involved in counteracting adverse growth conditions, and in particular H-NS is able to sense shifts of temperature, osmolarity, and $\mathrm{pH}$ [44]. Thus, (p)ppGpp, making H-NS decrease below a certain threshold level, might, in turn, determine a derepression of all the genes, commonly silenced by H-NS, which are essential to counteracting stress situation. This assumption is supported by the observation that other nucleoid-associated proteins, mostly those with pronounced regulatory functions such as FIS, Dps, DnaA, StpA, and Hfq, are selectively up- or down-regulated by (p)ppGpp [11]. In particular, FIS (Factor for Inversion Stimulation) was found to stimulate $h n s$ expression limited to the exponential phase of growth [45]. The lack of FIS in stationary phase cells might account for hns expression patterns of wt and relA/spoT strains that become similar as the cell density increases ( Abs $_{600 \mathrm{~nm}}>1.5$, Figure 2D). The fact is that (p)ppGpp represses both fis and hns promoters, thereby allowing us to speculate on the occurrence that the hns gene is subjected to a dual negative action by (p)ppGpp: (i) by directly impacting the intrinsic activity of $h n s$ promoter; (ii) by depleting the $h n s$ gene of its natural activator FIS.

Importantly, an adaptative stress-response also takes place when pathogenic bacteria face up transitions from free-living to host-associated states. In this contest, H-NS has been found in important human pathogens such as S. typhimurium, S. flexneri, V. cholerae, Y. pesti, P. multocida and, consistently, many genes controlled by this protein turn out to be virulence genes or genes expressing potential pathogenicity determinants [46-51]. The response of $h n s$ promoter to (p)ppGpp, investigated through an in vitro transcription system (Figure 4), undeniably indicates that the inhibition exerted by this modified nucleotide is direct and promoter specific. In fact, a $50 \%$ loss of promoter activity is observed at $\sim 400 \mu \mathrm{M}$ of (p)ppGpp and the hns transcription declines as much as $5-10 \%$ for higher (p)ppGpp concentrations. These amounts of (p)ppGpp are very close to those used in other in vitro studies $[11,52,53]$ and consistent with the value $(\sim 0.9-1 \mathrm{mM})$ measured in vivo during the stringent response [42,54].

The failure to identify $h n s$ as a (p)ppGpp-responsive gene using transcriptomics techniques as RNA-seq [11] and microarrays [12] was quite unexpected. Possible explanations for conflicting results are reported below. As already stated, Sanchez-Vazquez et al. [11] estimated the $h n s$ mRNA level at 5 and $10 \mathrm{~min}$ after the production of (p)ppGpp by an inducible relA plasmid system. Using an analogous experimental approach (Figure 3A), we show that at least 20-25 min is required to detect significant differences in $h n s$ expression between induced and not-induced cells. Concerning the study by Aberg et al. [12], the total RNA for DNA chip and Reverse Transcriptase PCR experiments was extracted from cells in stationary phase $\left(\mathrm{Abs}_{600}=1.5\right)$. Under our experimental conditions (Figure $\left.2 \mathrm{~B}, \mathrm{D}\right)$, at cell density ranging from $\mathrm{Abs}_{600}=1.5$ to $\mathrm{Abs}_{600}=3.0$, the level of $h n s$ transcript of wt strain is comparable with that of relA/spoT double mutant, whereas a differential expression is observed mainly in exponential phase of growth. Thus, because of narrow time window or cell status, the in vivo (p)ppGpp-mediated regulation of $h n s$ might have been overlooked in previous studies [11,12]. Our results suggest that stationary phase cells slow down the $h n s$ transcription rate in a (p)ppGpp-independent manner probably because, at this time, other factors (i.e., the lack of FIS) may contribute mostly to the regulation of this gene. Remarkably, H-NS is also able to bind and repress transcription from its own promoter [15] and it was found to accumulate when cells enter the stationary phase [55]. However, the intracellular levels of this protein during growth-curve still remain a matter of debate [56-58]. Thus, an increase in H-NS level would enhance the autorepression providing an explanation for the decline of $h n s$ mRNA in 
both wt and relA/spoT strains, as observed at the onset of stationary phase $\left(\mathrm{Abs}_{600}=1.5\right.$ in Figure $\left.2 \mathrm{D}\right)$. Ultimately, stationary cells (as the starved ones), characterized by a low growth rate and a reduced DNA synthesis need a poor demand for de novo production of the nucleoid protein H-NS.

Recently, a large collection of (p)ppGpp directly regulated genes has been obtained thanks to an extensive in vitro transcription analysis carried out on more than 100 promoters (not including hns) whose in vivo expression was affected at least twofold by the modified nucleotide [11]. Although not being conclusive, given the limited number of genes tested, this study permitted the identification of some DNA sequence signatures characteristic of the three classes of promoters: inhibited, activated, and unaffected. Thus, the sequence of hns promoter was superimposed to the histograms of base distributions for promoters inhibited by (p)ppGpp as determined by Sanchez-Vazquez et al. [11]. This comparison, illustrated as bar graphs in Figure 6, includes the -10 promoter element (the TATA box) and the transcriptional start site (TSS) region encompassing the discriminator (from position -1 to position -6 and the initial transcribed sequence. Concerning the -10 consensus sequence, although three bases, the thymines at positions -12 and -7 and the adenine at position -11 , are poorly informative due to the high sequence conservation of TATA box in all promoters, hns shows an adenine at position -8 that was found to interact with RNAP [59] and is strongly favored in promoters negatively affected by (p)ppGpp (Figure 6B). Furthermore, the cytosine at position -13 (extended -10 region) and the spacer length of $17 \mathrm{bp}$ are compatible with promoters repressed by (p)ppGpp (Figure 6A). The discriminator region with its high $\mathrm{G}+\mathrm{C}$ content is a potential disadvantage to strand-separation at transcription initiation and has been long related with (p)ppGpp down-regulation [60]. Relatively to hns sequence, three cytosines occupy positions $-4,-3$ and -1 , respectively, thus contributing to constitute a robust discriminator (Figure $6 \mathrm{C}$ ). Notably, the cytosine at position -1 was found at very high frequency $(\sim 85 \%)$ in inhibited promoters since its presence is required to stabilize the incoming rNTP. Conservation of C-1 is crucial given that it reduces the abortive products formation and accelerates the RNAP escape from those promoters as the ones negatively controlled by (p)ppGpp that show short-lived open complexes [61,62]. According to these findings, band shift assays clearly indicate that the stability and/or formation of hns promoter-RNAP complexes is impaired by the presence of the modified nucleotide (Figure 5), given an explanation for the (p)ppGpp-dependent reduction in the in vitro transcriptional activity of $h n s$ promoter (Figure 4). Furthermore, the $h n s$ sequence analysis reveals that the initial rNTPs incorporated into hns mRNA (Figure $6 \mathrm{C}$, positions A+2, C+3 and A+6) well match with transcripts repressed by this alarmone. Regarding the -35 consensus hexamer, no significant sequence difference has been observed between activated and inhibited promoters suggesting that this element does not actively participate to (p)ppGpp regulation [11]. Summarizing, the hns promoter exhibits the primary sequence determinants accounting for a direct regulation by (p)ppGpp as validated through in vitro experiments (Figures 4 and 5).

In addition to (p)ppGpp, a second effector, playing a crucial role during the stringent response, is the transcription factor DksA. This small protein $(17 \mathrm{kDa})$ binds RNAP through the secondary channel [63] and largely contributes to create, at protein-protein contact region, the (p)ppGpp binding site 2 [10]. Differently, site 1 is located on RNAP at the interface between $\beta^{\prime}$ and $\omega$ subunits and does not need additional proteins to be formed [9]. DksA was found to function in synergy with (p)ppGpp strengthening its effects, either positive or negative, on transcription. Thus, DksA and (p)ppGpp together work better than either alone and up- or down-regulation depends on the intrinsic kinetic properties of the distinctive promoter controlled by (p)ppGpp [7,64-67]. In this context, there is no evidence that the preparations of RNAP, both the commercial and purified one in our laboratory used in in vitro assays (Figures 4 and 5), contain appreciable amounts of DksA, and as a consequence these enzymes lack the (p)ppGpp binding site 2. Importantly, site 2 was found to greatly affect RNAP activity, more than site 1, particularly at inhibited promoters [10]. Thus, it is reasonable to assume that the (p)ppGpp-dependent effect, observed in the in vitro transcription assays (Figure 4), results from the occupancy of the only site 1 , suggesting that repression of $h n$ s promoter activity might be underestimated and/or taking place at lower (p)ppGpp concentration in the presence of DksA as 
previously described for rRNA genes [65]. Ultimately, the (p)ppGpp-DksA synergism, better and promptly than (p)ppGpp alone, could fine tune the hns transcription rate in response to small changes of intracellular levels of $\mathrm{p}(\mathrm{p}) \mathrm{ppGpp}$ as observed in vivo using drugs addition, relA/spoT mutants and RelA over-expressing systems (Figures 1-3). The molecular dissection of (p)ppGpp-DksA interplay might be the topic for a future study.
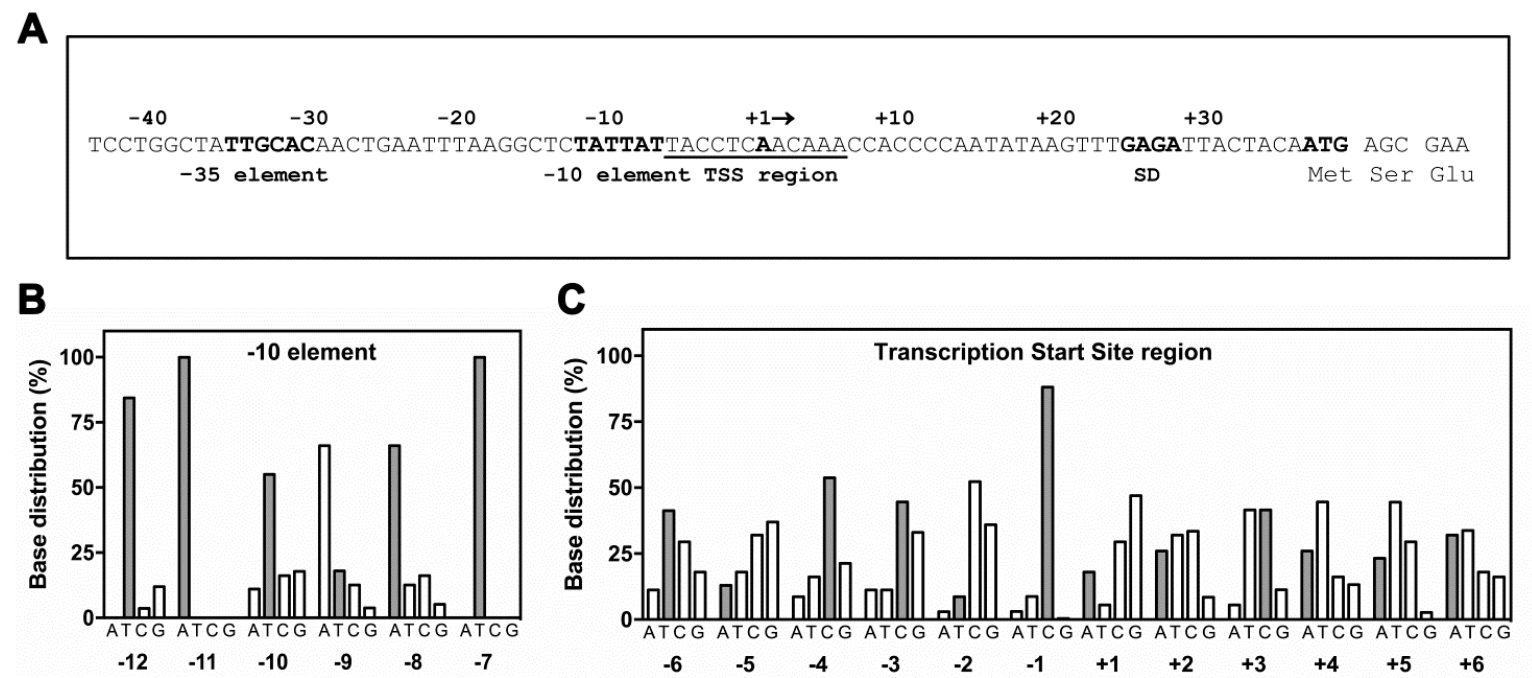

Figure 6. Matching of $h n s$ promoter sequence with base distributions for (p)ppGpp-inhibited promoters. The hns promoter hexamers ( -35 and -10$)$, Transcription Start Site (TSS) region including the Discriminator, Shine-Dalgarno Sequence (SD) and DNA sequence encoding for the first three amino acids of H-NS are shown (A). The $h n s$ nucleotide sequence (gray bars) at -10 promoter motif (B) and TSS region (C) was overlaid with base distribution histograms for ppGpp/DskA inhibited promoters as freely redrawn using data by Sanchez-Vazqueza et al. [11].

Author Contributions: A.B., M.G., A.F. and M.F. designed and performed experiments, contributed to analyze and interpret data, and critically reviewed the drafted manuscript. M.F. supervised the whole work, prepared figures, and wrote the paper. All authors have read and agreed to the published version of the manuscript.

Funding: This work was supported by grants Fondi Ricerca Ateneo (FAR, n. BVI000002) from Camerino University to MF and partially by "Convenzione Ecolpidiense" sponsored by Ecoelpidiense, P.S. Elpidio (FM), Italy.

Acknowledgments: We thank N.P. Higgins (University of Alabama at Birmingham, USA) for providing us the relA/spoT strains and V. Napolioni (University of Camerino) and E. Totò (Fermo, Italy) for linguistic revision.

Conflicts of Interest: The authors declare no potential conflicts of interest.

\section{References}

1. Potrykus, K.; Cashel, M. (p)ppGpp: Still magical? Annu. Rev. Microbiol. 2008, 62, 35-51. [CrossRef]

2. Liu, K.; Bittner, A.N.; Wang, J.D. Diversity in (p)ppGpp metabolism and effectors. Curr. Opin. Microbiol. 2015, 24, 72-79. [CrossRef] [PubMed]

3. Steinchen, W.; Bange, G. The magic dance of the alarmones (p)ppGpp. Mol. Microbiol. 2016, 101, 531-544. [CrossRef] [PubMed]

4. Ronneau, S.; Hallez, R. Make and break the alarmone: Regulation of (p)ppGpp synthetase/hydrolase enzymes in bacteria. FEMS Microbiol. Rev. 2019, 43, 389-400. [CrossRef] [PubMed]

5. Winther, K.S.; Roghanian, M.; Gerdes, K. Activation of the stringent response by loading of RelA tRNA complexes at the ribosomal A-site. Mol. Cell. 2018, 70, 95-105. [CrossRef]

6. Hauryliuk, V.; Atkinson, G.C.; Murakami, K.S.; Tenson, T.; Gerdes, K. Recent functional insights into the role of (p)ppGpp in bacterial physiology. Nat. Rev. Microbiol. 2015, 13, 298-309. [CrossRef]

7. Haugen, S.P.; Ross, W.; Gourse, R.L. Advances in bacterial promoter recognition and its control by factors that do not bind DNA. Nat. Rev. Microbiol. 2008, 6, 507-519. [CrossRef] 
8. Gourse, R.L.; Chen, A.Y.; Gopalkrishnan, S.; Sanchez-Vazquez, P.; Myers, A.; Ross, W. Transcriptional Responses to ppGpp and DksA. Annu. Rev. Microbiol. 2018, 72, 163-184. [CrossRef]

9. Ross, W.; Vrentas, C.E.; Sanchez-Vazquez, P.; Gaal, T.; Gourse, R.L. The magic spot: A ppGpp binding site on E. coli RNA polymerase responsible for regulation of transcription initiation. Mol. Cell. 2013, 50, 420-429. [CrossRef]

10. Ross, W.; Sanchez-Vazquez, P.; Chen, AY.; Lee, JH.; Burgos, HL.; Gourse, R.L. ppGpp binding to a site at the RNAP-DksA interface accounts for its dramatic effects on transcription initiation during the stringent response. Mol. Cell. 2016, 62, 811-823. [CrossRef]

11. Sanchez-Vazquez, P.; Dewey, C.N.; Kitten, N.; Ross, W.; Gourse, R.L. Genome-wide effects on Escherichia coli transcription from ppGpp binding to its two sites on RNA polymerase. Proc. Natl. Acad. Sci. USA 2019, 116, 8310-8319. [CrossRef] [PubMed]

12. Åberg, A.; Fernandez-Vazquez, J.; Cabrer-Panes, J.D.; Sanchez, A.; Balsalobre, C. Similar and Divergent Effects of ppGpp and DksA Deficiencies on Transcription in Escherichia coli. J. Bacteriol. 2009, 191, 3226-3236. [CrossRef]

13. Pon, C.L.; Calogero, R.A.; Gualerzi, C.O. Identification, cloning, nucleotide sequence and chromosomal map location of hns, the structural gene for Escherichia coli DNA-binding protein H-NS. Mol. Gen. Genet. 1988, 212, 199-202. [CrossRef] [PubMed]

14. Falconi, M.; Gualtieri, M.T.; La Teana, A.; Losso, M.A.; Pon, C.L. Proteins from the prokaryotic nucleoid: Primary and quaternary structure of the15-kD Escherichia coli DNA binding protein H-NS. Mol. Microbiol. 1988, 2, 323-329. [CrossRef] [PubMed]

15. Falconi, M.; Higgins, N.P.; Spurio, R.; Pon, C.L.; Gualerzi, C.O. Expression of the gene encoding the major bacterial nucleoid protein H-NS is subject to transcriptional auto-repression. Mol. Microbiol. 1993, 10, 273-282. [CrossRef] [PubMed]

16. Dorman, C.J. H-NS, the genome sentinel. Nat. Rev. Microbiol. 2007, 5, 157-161. [CrossRef]

17. Dillon, S.C.; Dorman, C.J. Bacterial nucleoid-associated proteins, nucleoid structure and gene expression. Nat. Rev. Microbiol. 2010, 8, 185-195. [CrossRef]

18. Rimsky, S.; Travers, A. Pervasive regulation of nucleoid structure and function by nucleoid-associated proteins. Curr. Opin. Microbiol. 2011, 14, 136-141. [CrossRef]

19. Atlung, T.; Ingmer, H. H-NS: A modulator of environmentally regulated gene expression. Mol. Microbiol. 1997, 24, 7-17. [CrossRef]

20. Yamada, H.; Muramatsu, S.; Mizuno, T. An Escherichia coli protein that preferentially binds to sharply curved DNA. J. Biochem. 1990, 108, 420-425. [CrossRef]

21. Gordon, B.R.; Li, Y.; Cote, A.; Weirauch, M.T.; Ding, P.; Hughes, T.R.; Navarre, W.W.; Xia, B.; Liu, J. Structural basis for recognition of AT-rich DNA by unrelated xenogeneic silencing proteins. Proc. Natl. Acad. Sci. USA 2011, 108, 10690-10695. [CrossRef] [PubMed]

22. Spurio, R.; Falconi, M.; Brandi, A.; Pon, L.C.; Gualerzi, C.O. The oligomeric structure of nucleoid protein H-NS is necessary for recognition of intrinsically curved DNA and for DNA bending. EMBO J. 1997, 16, 1795-1805. [CrossRef] [PubMed]

23. Kahramanoglou, C.; Seshasayee, A.S.; Prieto, A.I.; Ibberson, D.; Schmidt, S.; Zimmermann, J.; Benes, V.; Fraser, G.M.; Luscombe, N.M. Direct and indirect effects of H-NS and Fis on global gene expression control in Escherichia coli. Nucleic Acids Res. 2011, 39, 2073-2091. [CrossRef] [PubMed]

24. van der Valk, R.A.; Vreede, J.; Qin, L.; Moolenaar, G.F.; Hofmann, A.; Goosen, N.; Dame, R.T. Mechanism of environmentally driven conformational changes that modulate H-NS DNA-bridging activity. eLife 2017, 6, e27369. [CrossRef]

25. Shahul Hameed, U.F.; Liao, C.; Radhakrishnan, A.K.; Huser, F.; Aljedani, S.S.; Zhao, X.; Momin, A.A.; Melo, F.A.; Guo, X.; Brooks, C.; et al. H-NS uses an autoinhibitory conformational switch for environmentcontrolled gene silencing. Nucleic Acids Res. 2019, 47, 2666-2680. [CrossRef]

26. Ishihama, A.; Kori, A.; Koshio, E.; Yamada, K.; Maeda, H.; Shimada, T.; Makinoshima, H.; Iwata, A.; Fujita, N. Intracellular concentrations of transcription factors in Escherichia coli: 65 species with known regulatory functions. J. Bacteriol. 2014, 196, 2718-2727. [CrossRef]

27. Shimada, T.; Bridier, A.; Briandet, R.; Ishihama, A. Novel roles of LeuO in transcription regulation in E. coli: Genome antagonistic interplay with the universal silencer H-NS. Mol. Microbiol. 2011, 82, 376-397. [CrossRef] 
28. Navarre, W.W.; McClelland, M.; Libby, S.J.; Fang, F.C. Silencing of xenogeneic DNA by H-NS-facilitation of lateral gene transfer in bacteria by a defense system that recognizes foreign DNA. Genes Dev. 2007, 21, 1456-1471. [CrossRef]

29. Ali, S.S.; Xia, B.; Liu, J.; Navarre, W.W. Silencing of foreign DNA in bacteria. Curr. Opin. Microbiol. 2012, 15, 175-181. [CrossRef]

30. Brandi, A.; Giangrossi, M.; Giuliodori, A.M.; Falconi, M. An Interplay among FIS, H-NS, and Guanosine Tetraphosphate Modulates Transcription of the Escherichia coli cspA Gene under Physiological Growth Conditions. Front. Mol. Biosci. 2016, 3, 19. [CrossRef]

31. Cammack, K.A.; Wade, H.E. The sedimentation behaviour of ribonuclease-active and -inactive ribosomes from bacteria. Biochem. J. 1965, 96, 671-680. [CrossRef] [PubMed]

32. Sarubbi, E.; Kenneth, E.R.; Cashel, M. Basal ppGpp level adjustment shown by new spoT mutants affect steady state growth rates and rrnA ribosomal promoter regulation in Escherichia coli. Mol. Gen. Genet. 1988, 213, 214-222. [CrossRef] [PubMed]

33. Xiao, H.; Kalman, M.; Ikehara, K.; Zemel, S.; Glaser, G.; Cashel, M. Residual guanosine 3',5'-bispyrophosphate synthetic activity of relA null mutants can be eliminated by spoT null mutations. J. Biol. Chem. 1991, 266, 5980-5990. [PubMed]

34. Wright, B.E.; Minnick, M.F. Reversion rates in a leuB auxotroph of Escherichia coli K-12 correlate with ppGpp levels during exponential growth. Microbiology 1997, 143, 847-854. [CrossRef] [PubMed]

35. Tedin, K.; Witte, A.; Reisinger, G.; Lubitz, W.; Bläsi, U. Evaluation of the E. coli rrnB P1 promoter and phage-derived lysis genes for the use in a biological containment system: A concept study. J. Biotechnol. 1995, 39, 137-148. [CrossRef]

36. Sambrook, J.; Russell, D.W. Molecular Cloning. A Laboratory Manual; CSHL Press: Cold Spring Harbor, NY, USA, 2011.

37. Brandi, A.; Giangrossi, M.; Paoloni, S.; Spurio, R.; Giuliodori, A.M.; Pon, C.L.; Gualerzi, C.O. Transcriptional and post-transcriptional events trigger de novo infB expression in cold stressed Escherichia coli. Nucleic Acids Res. 2019, 47, 4638-4651. [CrossRef]

38. Spurio, R.; Dürrenberger, M.; Falconi, M.; La Teana, A.; Pon, C.L.; Gualerzi, C.O. Lethal overproduction of the Escherichia coli nucleoid protein H-NS: Ultramicroscopic and molecular autopsy. Mol. Gen. Genet. 1992, 231, 201-211. [CrossRef]

39. Sarubbi, E.; Rudd, K.E.; Xiao, H.; Ikehara, K.; Kalman, M.; Cashell, M. Characterization of the spoT gene of Escherichia coli. J. Biol. Chem. 1989, 264, 15074-15082. [PubMed]

40. Gross, C.; Engbaek, F.; Flammang, T.; Burgess, R. Rapid micromethod for the purification of Escherichia coli Ribonucleic Acid Polymerase and the preparation of bacterial extracts active in ribonucleic acid synthesis. J. Bacteriol. 1976, 128, 382-389. [CrossRef] [PubMed]

41. Muto, A.; Kimura, A.; Osawa, S. Effects of some antibiotics on the stringent control of RNA synthesis in Escherichia coli. Mol. Gen. Genet. 1975, 139, 321-327. [CrossRef]

42. Ryals, J.; Little, R.; Bremer, H. Control of rRNA and tRNA syntheses in Escherichia coli by guanosine tetraphosphate. J. Bacteriol. 1982, 151, 1261-1268. [CrossRef] [PubMed]

43. Hamming, J.; Geert, A.B.; Gruber, M. E. coli RNA polymerase-rRNA promoter interaction and the effect of ppGpp. Nucleic Acids Res. 1980, 8, 3947-3963. [CrossRef] [PubMed]

44. Hommais, F.; Krin, E.; Laurent-Winter, C.; Soutourina, O.; Malpertuy, A.; Le Caer, J.P.; Danchin, A.; Bertin, P. Large-scale monitoring of pleiotropic regulation of gene expression by the prokaryotic nucleoid-associated protein, H-NS. Mol. Microbiol. 2001, 40, 20-36. [CrossRef] [PubMed]

45. Falconi, M.; Brandi, A.; La Teana, A.; Gualerzi, C.O.; Pon, C.L. Antagonistic involvement of FIS and H-NS proteins in the transcriptional control of hns expression. Mol. Microbiol. 1996, 19, 965-975. [CrossRef]

46. Falconi, M.; Colonna, B.; Prosseda, G.; Micheli, G.; Gualerzi, C.O. Thermoregulation of Shigella and Escherichia coli EIEC pathogenicity. A temperature-dependent structural transition of DNA modulates accessibility of virF promoter to transcriptional repressor H-NS. EMBO J. 1998, 17, 7033-7043. [CrossRef]

47. Madrid, C.; Nieto, J.M.; Paytubi, S.; Falconi, M.; Gualerzi, C.O.; Juárez, A. Temperature- and H-NS-dependent regulation of a plasmid-encoded virulence operon expressing Escherichia coli hemolysin. J. Bacteriol. 2002, 184, 5058-5066. [CrossRef]

48. Beloin, C.; McKenna, S.; Dorman, C.J. Molecular dissection of VirB a key regulator of the virulence cascade of Shigella flexneri. J. Biol. Chem. 2002, 277, 15333-15344. [CrossRef] 
49. Walthers, D.; Carrol, R.K.; Navarre, W.W.; Libby, S.J.; Fang, F.C.; Kenney, L.J. The response regulator SsrB activates expression of diverse Salmonella pathogenicity island 2 promoters and counters silencing by the nucleoid-associated protein H-NS. Mol. Microbiol. 2007, 65, 477-493. [CrossRef]

50. Tran, C.N.; Giangrossi, M.; Prosseda, G.; Brandi, A.; Di Martino, M.L.; Colonna, B.; Falconi, M. A multifactor regulatory circuit involving H-NS, VirF and an antisense RNA modulates transcription of the virulence gene icsA of Shigella flexneri. Nucleic Acids Res. 2011, 39, 8122-8134. [CrossRef]

51. Engstrom, M.D.; Mobley, H.L. Regulation of Expression of Uropathogenic Escherichia coli Nonfimbrial Adhesin TosA by PapB Homolog TosR in Conjunction with H-NS and Lrp. Infect. Immun. 2016, 84, 811-821. [CrossRef]

52. Heinemann, M.; Wagner, R. Guanosine 3' 3' $^{\prime}$-bis(diphosphate) (ppGpp)-dependent inhibition of transcription from stringently controlled Escherichia coli promoters can be explained by an altered initiation pathway that traps RNA polymerase. FEBS 1997, 247, 990-999. [CrossRef] [PubMed]

53. Łyżeń, R.; Maitra, A.; Milewska, K.; Kochanowska-Łyżeń, M.; Hernandez, V.J.; Szalewska-Pałasz, A. The dual role of DksA protein in the regulation of Escherichia coli pArgX promoter. Nucleic Acids Res. 2016, 44, 10316-10325. [CrossRef] [PubMed]

54. Traxler, M.F.; Summers, S.M.; Nguyen, H.T.; Zacharia, V.M.; Hightower, G.A.; Smith, J.T.; Conway, T. The global, ppGpp-mediated stringent response to amino acid starvation in Escherichia coli. Mol. Microbiol. 2008, 68, 1128-1148. [CrossRef] [PubMed]

55. Spassky, A.; Rimsky, S.; Garreau, H.; Buc, H. H1a, an E. coli DNA-binding protein which accumulates in stationary phase, strongly compacts DNA in vitro. Nucleic Acids Res. 1984, 12, 5321-5340. [CrossRef]

56. Dersch, P.; Schmidt, K.; Bremer, E. Synthesis of the Escherichia coli K-12 nucleoid-associated DNA-binding protein H-NS is subjected to growth-phase control and autoregulation. Mol. Microbiol. 1993, 8, 875-889. [CrossRef]

57. Free, A.; Dorman, C.J. Coupling of Escherichia coli hns mRNA levels to DNA synthesis by autoregulation: Implications for growth phase control. Mol. Microbiol. 1995, 18, 101-113. [CrossRef]

58. Brambilla, E.; Sclavi, B. Gene Regulation by H-NS as a Function of Growth Conditions Depends on Chromosomal Position in Escherichia coli. G3 Genes Genomes Genet. 2015, 5, 605-614. [CrossRef]

59. Feklistov, A.; Darst, S.A. Structural basis for promoter -10 element recognition by the bacterial RNA polymerase $\sigma$ subunit. Cell 2011, 147, 1257-1269. [CrossRef]

60. Travers, A.A. Promoter sequence for stringent control of bacterial ribonucleic acid synthesis. J. Bacteriol. 1980, 141, 973-976. [CrossRef] [PubMed]

61. Gleghorn, M.L.; Davydova, E.K.; Basu, R.; Rothman-Denes, L.B.; Murakami, K.S. X-ray crystal structures elucidate the nucleotidyl transfer reaction of transcript initiation using two nucleotides. Proc. Natl. Acad. Sci. USA 2011, 108, 3566-3571. [CrossRef]

62. Winkelman, J.T.; Chandrangsu, P.; Ross, W.; Gourse, R.L. Open complex scrunching before nucleotide addition accounts for the unusual transcription start site of E. coli ribosomal RNA promoters. Proc. Natl. Acad. Sci. USA 2016, 113, E1787-E1795. [CrossRef] [PubMed]

63. Lennon, C.W.; Ross, W.; Martin-Tumasz, S.; Toulokhonov, I.; Vrentas, C.E.; Rutherford, S.T.; Lee, J.H.; Butcher, S.E.; Gourse, R.L. Direct interactions between the coiled-coil tip of DksA and the trigger loop of RNA polymerase mediate transcriptional regulation. Genes Dev. 2012, 26, 2634-2646. [CrossRef] [PubMed]

64. Perederina, A.; Svetlov, V.; Vassylyeva, M.N.; Tahirov, T.H.; Yokoyama, S.; Artsimovitch, I.; Vassylyev, D.G. Regulation through the secondary channel-structural framework for ppGpp-DksA synergism during transcription. Cell 2004, 118, 297-309. [CrossRef] [PubMed]

65. Paul, B.J.; Barker, M.M.; Ross, W.; Schneider, D.A.; Webb, C.; Foster, J.W.; Gourse, R.L. DksA: A critical component of the transcription initiation machinery that potentiates the regulation of rRNA promoters by ppGpp and the initiating NTP. Cell 2004, 118, 311-322. [CrossRef]

66. Roberts, J.W. Promoter-specific control of E. coli RNA polymerase by ppGpp and a general transcription factor. Genes Dev. 2009, 23, 143-146. [CrossRef]

67. Rutherford, S.T.; Villers, C.L.; Lee, J.H.; Ross, W.; Gourse, R.L. Allosteric control of Escherichia coli rRNA promoter complexes by DksA. Genes Dev. 2009, 23, 236-248. [CrossRef]

(C) 2020 by the authors. Licensee MDPI, Basel, Switzerland. This article is an open access article distributed under the terms and conditions of the Creative Commons Attribution (CC BY) license (http://creativecommons.org/licenses/by/4.0/). 